\title{
The role of subjectivity in teacher expertise development: Mindfully embracing the "black sheep" of educational research
}

DOI 10.1515/ijtr-2016-0003

received February 2016; accepted April 2016

\begin{abstract}
In Western cultures, subjectivity has often been seen as the "black sheep" of educational research because of its heavy emphasis on objectivity. Consequently many research initiatives in education share the assumption that objective reasoning should play a central role. However, mentoring teachers' practice improvement research often requires us to go beyond the objective dimension and encompass the subjective dimension of the research process such as teachers' intuition, tacit knowledge and personal meaning-making. The challenge that lies in front of us is how to mindfully make sense of the role of subjectivity in teacher expertise development. This paper examines this issue in terms of three case studies of in-service teachers' action research projects and points to what it takes for us to mindfully embrace subjectivity in mentoring teachers' practice improvement research.
\end{abstract}

Keywords: Subjectivity; Action research; Teacher expertise development; Objectivity; Intersubjectivity

\section{Introduction}

This paper introduces a study that looked into the role of subjectivity in teachers' action research projects and discusses how we could mindfully embrace subjectivity to meaningfully promote teacher expertise development in teacher education programs. According to Noffke (2009),

* Corresponding author: Noriyuki Inoue, University of San Diego 5998, Alcala Park, San Diego, CA 92110, E-mail: inoue@sandiego. edu the action research process is characterised by the personal, professional and political dimensions. Among them, the personal dimension includes a wide variety of intrapersonal issues that emerges and is known to dynamically interacts with the other two dimensions in the research process. Within the personal dimension, educators' personally constructed meanings and perceptions of reality could guide a wide variety of decisions and reflections involved in the multi-cyclic research process. In action research, this intrapersonal process can function to catalyse the process of inside-out transformations in conjunction with its social and political dimensions (Torbert, 2004). It can be seen that such a personal inner-working in a practice-linked research experience sets an important stage for teachers to develop personally, professionally and socially valuable forms of knowledge (Farren \& Crotty, 2014).

If we narrowly define teachers' action research in terms of how to improve educational practices on an objective dimension, it becomes merely another attempt to make educational practice more "scientific". However, the gist of action research can be considered to bring out personal, social and political transformations by involving "I" at the heart of its process (Whitehead, 2006). Therefore, it is essential to develop a better and deeper understanding of the role of subjectivity in teachers' action research projects as well as how we could mindfully embrace the subjective dimension of action research for promoting teacher expertise development.

In traditional educational research, however, subjectivity has been its "black sheep" because of its heavy emphasis on objectivity in the field (see Gergen, 2001; Drapeau, 2002; Ratner 2002). However, in many non-Western contexts, holistic integration of thinking, feeling, motivation and other functions of the mind is seen as an important foundation of educational practice and dialogues among teachers (Lewis, 1995; Reason, 2004). For instance, the Japanese culture emphasises organic and genuine integration of thinking with one's feeling with the term omoi - a deep-seated feeling integrated with 
one's thinking and personal experiences. In the Japanese culture it is common that professionals start their professional development and overcome real life challenges based on their omoi (Inoue, 2015; 2012). Omoi is considered to serve as an important starting point from which professional development efforts are supposed to happen. In schools, teachers often engage in a variety of professional development efforts while reflecting on their teaching and inner meaning-making based on their omoi.

This cultural concept is considered to be rooted in the particular epistemological tradition widespread in the East-Asian culture. In East Asian cultures the human mind is considered to be a holistic entity that is not independent of various functions of the body. It is believed that artificially detaching an objective thinking from diverse mental and bodily functioning is considered to be dangerous as it can make us lose sight of the holistic picture of our experiences. Humans are considered to function and make a variety of decisions based on such a holistic basis, which is often reflected as an underlying philosophy of a variety of practices in East Asian cultures (Inoue, 2012). Interestingly this view of human development has been recently receiving an increasing attention among educators in Western cultures (e.g.,. David, 2009; Jennings, 2015; Rechtschaffen, 2014).

Thus the challenge that lies in front of us is how to better understand the role of subjectivity involved in teacher expertise development especially in Western contexts. What is the nature of subjectivity that we should embrace to meaningfully promote teacher expertise development? How are we supposed to mentor teachers' action research projects by being mindful of the role of subjectivity involved in the process?

\section{Methods}

This study employed the case study method to answer the above questions. It involves three cases of beginning teachers' action research projects, from which the crosscase analysis was conducted to look for chains of evidence for meaningful patterns that emerge in the process (Yin, 1989; Miles \& Huberman, 1994). More specifically, the three cases were used to identify the common threads and themes that capture the roles of subjectivity in teacher expertise development.

All the cases of action research projects were chosen from a Masters program at a Higher Education Institution in Southern California in which conducting an action research project with at least two recursive phases is a required part of the graduation requirement. The three cases were identified from the author's advisees on the basis of how informative and representative they are in studying diverse challenges that beginning teachers encounter and overcome as transformative experiences in the action research process. The written notes of the advising sessions, emails and the teachers' action research papers served as the data for this study.

The following section describes the three cases used for the study. As is always the case, the three cases involved more details that were not included in the following description due to the space limitation. However, the following section was organized with an intention to convey most essential aspects of these cases for the purpose of this study.

\section{Three Cases}

\subsection{Case Study \#1: Jane}

Jane was a first year second grade teacher at a charter school in a low-income community. As she was close to completing her masters course work, she chose to conduct her action research project to help English language learners develop language skills and learn academic contents competently in her classes. She chose this topic based on her childhood memory of being surrounded by many unknowns and feeling anxiety in her school. To her advisor, she shared this deep-seated feeling and conveyed that she would like to help her students become free from such anxiety, which she described as unpacking and unloading her students" "backpacks".

For her action research, she chose to implement "Accountable Talk" in her classes, that is, promoting her students' development of academic language skills by modeling several specific language frames that her students could actually use in class discussions and making them accountable for the use of the academic language in her classes (e.g., "Could you explain why you claim...?”). She chose this approach in her action research because she was introduced to this idea in a district-based workshop and felt it would be a good approach for her to use to assist English language learners in her classes with diverse language needs, as evidenced in her needs assessment. Though the advisor was not clear whether the approach introduced by the school district best meets the needs of her students, it was agreed that she pursue the path especially because she felt highly confident that it would be the best way for her to meet the language needs 
of the students that she has been concerned about as the first year teacher.

In the first phase of the action research her students did show some improvement in the use of academic expressions that she introduced in Accountable Talk activities. However, she noticed they were using the academic expressions rather mindlessly and only in limited occasions. She increased the frequency of modeling the use of academic language in front of the students and gave more worksheets illustrating examples to her students, but she did not see significant improvement of her students' use of academic language in regular academic classes outside of the Accountable Talk activities. The analyses of the data gathered in her class evidenced the challenge she was facing.

Being at a loss, she came to an advising session and confessed that she had no idea what to do next. She was near to tears and confessed how tough it had been and how anxious she had been feeling as a first year teacher with so many language learners in her class. She and her advisor had a number of meetings to develop a new approach for her second phase. At this point, she and her advisor co-reflected on what actually happened in the first phase and agreed that the one-directional approach to model the Accountable Talk in front of her students could have made students consider the use of academic language as something that they should simply follow and thus could have served as the source of the problem. The phase 2 action plan co-developed in the advising sessions was to support the students' academic language development by capturing specific language needs of each of the language learners when they emerge in her class and scaffolding the students to express their ideas on the spot as she individually or collectively assists the students to use academic expressions as needed.

This capture-the-needs-and-scaffold-on-the-spot approach in the second phase was highly successful, and Jane observed much more frequent and authentic use of academic expressions by language learners throughout her classes. This finding was cross-validated by the students' academic performance and interview data. Jane re-gained confidence as a first year teacher and learned that she could use this scaffolding approach to support her students in many other occasions. She also learned that this multi-phase action research process to improve her teaching is a powerful way to improve her teaching and reduce the anxiety ("backpacks") of not only her students but also herself as a beginning teacher.

\subsection{Case Study \#2: Kim}

Kim was a second year, second grade teacher at a Catholic Elementary School in a low-income community. As she completed her Masters course work that offered her many different perspectives, the most important agenda for her, as a beginning teacher, was how to eliminate behavioral disturbances in some of her students and to help her students focus on their learning. She decided to conceptualize the goal of her action research as students' motivation - motivating her students to learn. In doing so, she strongly felt that effectively incorporating the Skinnerian style control system in her classroom would achieve the goal. Her approach was to praise the students who exhibited desirable behaviors but ignore the students who showed disturbances during her lessons. She was confident that this approach would work based on her 2-year teaching experience as well as the assessment of her students' behavioral needs and wanted to start the first phase of her action research in this way. Though her advisor was not sure if the Skinnerian control is the best action to meet the needs of the students she was adamant about using the approach. She revealed that it is how she learned to behave when she was a second grader.

As the advisor expected she failed to get students to improve their behaviors or become motivated to learn using the approach. The students showed more disturbing behaviors and her classroom lessons became more and more difficult. She tried different ways - giving new pencils instead of praise, giving meaningful feedback to negative behaviors instead of ignoring the behaviors, etc. - but she found that none of her approaches were working both in her experiences and her data analyses. She was totally lost after trying this approach in her classroom for about two months. She came to her advisor and talked about her struggles in her classroom. She was highly emotional in describing her frustration, disappointment and the sense of being lost. The advising session was mainly focused on listening to her but gradually went into sharing multiple stories of overcoming struggles in schools and brainstorming new approaches to overcome the struggles. She and her advisor discussed a wide variety of cases of her students' behaviors and the ways she could interact with the students for the second phase in reference to her experiences and the data she collected in the first phase.

The new approach that was agreed was to provide her students with opportunities to set their own behavioral goals and help them reflect on these goals. Rather than using the top-down reward-based approach, which she agreed never worked no matter how efficiently she tried to implement, she agreed that the reflection-based approach 
could be a much more meaningful solution that could totally change the nature of the process. In the approach her students were given time to set a behavioral goal at the beginning of the day such as not talking with their peers during her lesson, listening to other students carefully when others are speaking in her class and being respectful to everyone. She asked each student to write down the goal on the board so that other students could see the goal. At the end of the day, the students were asked to reflect on whether they accomplished the goal and think about what they should learn from the experience. She called this method a constructivist approach.

This constructivist approach became highly successful as time went by. She observed that her students became much more reflective and respectful in her classroom and the data she gathered evidenced her success in terms of their academic performance and classroom behaviors. Kim really embraced the moments of success. She was no longer a broken-hearted second year teacher. She learned not only that the constructivist approach was the key for eliminating behavioral disturbances but also that the failure could be overcome by transforming herself through deep reflections on her actions.

\subsection{Case Study \#3: Christy}

Christy was a second year mathematics teacher who teaches developmental level mathematics classes at a High School. Her main concern was to enable her students to become interested in mathematics. In her everyday teaching, she found that her students were not motivated to learn mathematics from numerous occasions of her teaching as well as the needs assessment she conducted. Through her reading and education classes, she learned about Japanese lesson study and decided to use the model to improve her lessons so that her students' interest in mathematics could be kindled.

First of all she decided to develop a series of mathematics problems that incorporate interesting situations from which she attempted to capture her students' interests. For her lesson study she developed a problem that asked what would be the height of dwarfs stacked together for the mission to save the sleeping beauty. Being a big fan of Disney movies she designed the mathematics problem feeling her students would be interested in the problem situation. After teaching the lesson she gave a survey to her students to assess their interest in the lesson. She also videotaped her lesson for the lesson study.

To discuss her lesson and the survey results she and her advisor organised a lesson study meeting with a group of local high and middle school mathematics teachers. In the session she first introduced the lesson plan and showed the video. Then she revealed the result of her survey: To her surprise her students' interest level was down when compared to the needs assessment data she had obtained prior to the lesson. After watching her video and hearing her presentation the lesson study group discussed various points and gave inputs on how she could improve her lesson and interactions with the students. The most important point that the group agreed on was that her students might have not felt the mathematics problem interesting even though it seemed interesting to her. In the videotaped lesson, her students, many of whom were male minority students, were just talking about the problem as if it were another math problem, with very little interest or regard to the situation of saving the sleeping beauty.

Through the lesson study discussions she realised that she should have designed the lesson based on what her students feel is interesting rather than what seems interesting to her and she should start from there in the next phase. She confessed later that this was quite a tough lesson for her. On her reflection, she started the next round of lessons based on what she observed to be her students' interest and developed problems that involved modeling physical motions such as creating a linear graph on the courtyard and modeling a basketball going into the goal. Eventually she found that these problems resulted in much more engagement and the higher interest level of her students according the survey data she collected. She continued this phase of her action research with renewed interest in her mathematics teaching.

In her action research Christy first failed to improve her practice because of her initial assumption on "an interesting mathematics problem". She assumed that what was interesting to her would be interesting to her students. However, she learned that her assumption was wrong as she failed to elicit students' interest in mathematical problem solving and learned that she was self-centered in conceptualising "interesting" mathematical problems. This was a tough message for her as a beginning teacher. After the failure in the first phase she did not respond to emails or get back to her advisor for quite a while. However, when she really digested the "lesson" from the first phase personally, she overcame the failure by planning and conducting the second phase to start from her students' interest, rather than hers. She learned how important it is to incorporate "other voices" in an inquiry to improve her teaching practice. 


\section{Findings: Key Themes}

The cross analyses revealed a set of themes that can help us better understand the roles that subjectivity play in the action research process. The following section discusses the themes that were extracted from the above case studies.

\subsection{Theme \#1: Subjective perception of the practice needs}

In the above three cases the teachers were highly subjective in their perceptions about their practice needs. Though they conducted needs assessment of their practices their scopes did not necessarily capture the actual needs of their teaching. Rather they seem to have developed their perceptions of the practice needs based on a highly subjective basis - often being pre-occupied by their students' weaknesses or an approach that they encountered and became committed personally. However at the same time, starting from what they saw as personally important seems to have furnished a sense of personal significance throughout the research process. Because of the limitations of their scopes they were not successful initially but they went through explorations of new approaches and self-transformations in the research process with the sense of significance. In other words the teachers did not necessarily capture essential practice needs but they did not give up easily even though they encountered challenges due to the fact that they had started the research process from what they whole-heartedly felt important. Thus it can be seen that the teachers' subjective perceptions of their practice needs gave an important contribution to the research process by setting an important affective tone at the outset of the process.

\subsection{Theme \#2: Subjective commitment to an action}

In the above three cases the teachers were highly subjective in choosing the action plan to improve their practices. It seems that the action plans that they developed were chosen based on what they personally or intuitively felt to be important. Again, they conducted needs assessment to guide their actions, but the scopes of their assessment were so limited that they did not necessarily guide their actions to meet the actual practice needs. It can be seen that their subjective commitment to a particular approach that they decided to employ seems to have been grounded in their personal history, their tacit knowledge about teaching as well as their deep-seated feeling (or omoi) about teaching. However even though they were highly subjective in choosing their action plans to improve their practices, since they were doing what they really cared about, the action research process seems to have entailed the sense of autonomy as well as the sense of personal significance. When the approach that they employed did not work they encountered significant cognitive dissonance that led them to explore new approaches by reconstructing their perspectives and knowledge base. Thus, the teachers' subjective commitment to actions that they envision to be personally important can be seen to have played an important role in getting the self-transformation process started.

\subsection{Theme \#3: Subjective ways to handle failures}

When the teachers failed to improve teaching in the first phase of their action research, there were highly personal ways of dealing with the challenges, struggles and failures. They used highly idiosyncratic ways to cope with the challenges. In the above cases the beginning teachers experienced different types of "drama" characterized by the sense of inadequacy and frustration as they witnessed that their first phase action did not result in expected outcomes. They became highly emotional sometimes and had to cope with the struggles to overcome the cognitive dissonance that they did not expect at the outset. The above three cases involved such subjective ways to handle failures and challenges involved in the action research process. However, they were also able to "rise from the ashes" and develop new approaches that reflected what they learned from their experiences. This can be seen to have created substantial opportunities for self-transformation and teacher expertise development in the research process. Thus, handling such personal "dramas" can be seen as an important part of the action research process. Consequently this aspect of the action research process required the advisor and each of the teachers to spend substantial time to co-reflect and co-develop new improved approaches, often in extended hours.

\subsection{Theme \#4: Subjective reconceptualis- ation of teaching}

When the teachers eventually overcame the "drama" by coming up with a more meaningful and reflective approach 
in the second phase, personal re-conceptualisation of their teaching - or their teacher identity - took place in all of the above cases. The teachers were highly idiosyncratic in exploring new ways of looking at their teaching and personally embracing the learning experiences in the process. This seems to have resulted in the development of tacit knowledge and teacher expertise that could have helped them meet the actual practice needs. Again such an awakening process was highly personal, and the teachers did not necessarily expect this when they started their action research projects. The action research process was characterised by such subjective ways for teachers to overcome the challenges and re-conceptualize their teaching practices. This was something that was not easily predicted in the beginning of the process.

\section{Discussions}

As we have seen subjectivity plays quite important roles in teachers' action research projects. As in the above cases the multi-phase action research process involved various moments where the teachers were challenged to examine their assumptions and reflect on how they should transform their practices. In the process, their subjective grasp of reality or their personal meaning making played quite significant roles at various stages of the research process. This implies that the teacher expertise development that takes place in action research is greatly dependent upon the diverse roles that the subjective dimension plays in the research process.

While it is important to acknowledge that an action research process is supposed to involve objective analyses of systematically collected data, the above cases indicate that such an objective dimension does not necessarily capture the whole story. What these case studies uncovered is the diverse roles that teachers' personal meaning-making play and how it can play essential roles in the research process. As the above themes capture, teachers' subjective perceptions about their practice greatly influenced their actions. Similarly, the teachers' highly idiosyncratic ways to cope with challenges that they encountered in their classrooms were quite an essential part of the story. While teachers' subjectivity has long been dismissed as a source of error or bias in traditional education research it would be important for us to understand the significant roles that subjectivity can play in teacher expertise development.

In doing what has been described above, it would be essential to better conceptualize the personal dimension of the ways teachers grasp their practice needs. For that purpose, I would like to introduce the Japanese term "jikkan". The direct translation of the term is "real sense" or "substantial feeling" but its closest English translation would be "gut-feeling" (Inoue, 2015; 2012). The teachers in the cases followed their jikkan - or gut feeling in the action research process while encountering a variety of challenges and snags in the process. In the process, they explored how to overcome their cognitive dissonance and learned new ways to conceptualize their teaching in ways that entailed new jikkan. Without such jikkan, what the teachers did and learned would not have been equipped with the personal sense of significance. Based on this East Asian concept, it can be seen that the teachers in the above case studies went through self-transformation because they started from the place where they felt jikkan and they did not lose sight of where they felt jikkan throughout the research process.

This is not to say that objective data analyses based on systematic data collection are not important. We need to recognise that the data that they collected and analyzed in the action research process (e.g, performance data, survey data, etc.) contributed to forming and transforming the teachers' jikkan. By collecting and analyzing data on an objective basis the teachers encountered a new face of reality and were challenged in their assumptions about their practices. However it is also true that the very scopes of their objective data-collections and analyses were limited by what they felt personally important no matter how objectively they attempted to conduct the assessment of their practices. In other words the choice of the data collection framework and their meaning-making could be seen to have originated in their jikkan that reflected their personally constructed understanding of their practices as well as the personal history of each teacher (e.g., the backpack experience). Similarly their choice of their actions ould be also seen to have originated in their jikkan or their personal preference of the conceptual framework that they had encountered at some point of their life (i.e., the accountable talk, the behavioristic framework, etc.) that they felt personally important. However, their jikkan did not stay unchanged. The process of their action research created a new kind of jikkan by giving them a "reality check" such as students not doing what they envisioned to be doing and seeing a lot of loose ends of their actions during the implementation, from which new jikkan gradually overrode the old one. In other words, it can be seen that their action research projects have made an impact on the improvement of their teaching since it offered a systematic opportunities to obtain new jikkan by being confronted with the data that portrayed unanticipated 
stories and exploring how to overcome the gap that they encountered regarding the issues that they felt personally important.

In the traditional Western epistemology, objectivity and subjectivity are seen to be antithetical to each other. Objectivity has thus enjoyed the-winner-takes-all status over subjectivity in traditional educational research. This study suggests that bringing the subjective dimension into the process of advising action research can play an important role in promoting the process of teacher expertise development in action research. This points to the importance of mindfully reflecting on the diverse roles that teacher subjectivity can play when we mentor teachers' action research projects.

One thing that we need to be careful here is that looking at only one side of the seemingly antithetical relationship between subjectivity and objectivity could blind our perspective. In teachers' action research projects, subjectivity and objectivity could be seen to form a dynamic balance between them, as objective analyses of data and subjective perceptions of reality dialectically impact each other. In advising teachers' action research projects, encompassing these seemingly opposite entities of human life could help teachers mindfully "dance" between the subjective world and the objective world to move forward in their endeavors (Inoue, 2015). For truly improving educational practices through research, therefore, it would be important to assume that what the objective data suggests and teachers' personal meaning-making unfolds itself as the action research process proceeds to overcome the gap. As we have seen in the above cases, this balancing job can be highly complex and non-linear, as represented in the following Figure 1.

In navigating through such complexity it would be important to assume that the teachers' meaning-making process involves much turbulence throughout the process where the objective world and the subjective

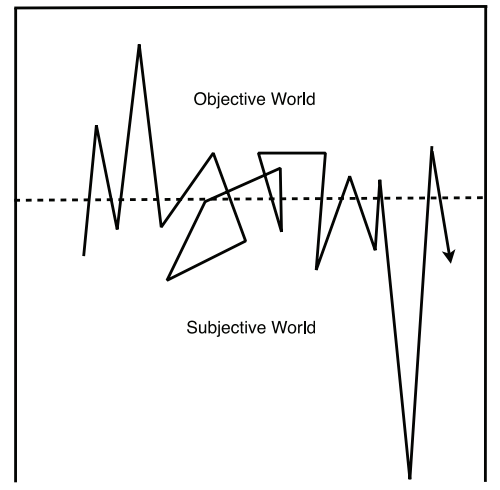

Figure 1: Dynamic interplays between objectivity and subjectivity world dynamically interact and collide with each other. If we look at the overall picture of teacher development, its trajectory could involve many collections of upward and downward trends where teachers dance between subjectivity and objectivity while engaging in a wide variety of personal meaning-making processes. Thus only one session of action research advising could encompass merely a part of the whole story. As in the hypothetical figure below, we need to always be mindful that the whole story can be much more complex and assume that there can be a bigger picture that would gradually unfold as teachers go through personal journeys to improve their practices, as was the case in the above three cases.

Finally, in the above three cases, what made the difference can be attributed to the co-reflections that the action researchers engaged in with their advisor. This implies that one of the key elements for promoting self-transformation in teachers and teacher expertise development through action research advising could be such intersubjectivity where the teachers and their advisor open up the subjective dimension and address different psychological needs of the action researcher through co-reflection on the complexity of the research process. In advising teachers' action research projects, such intersubjectivity can serve as an essential arena for teachers to explore and develop new meanings out of their experiences and overcome cognitive dissonance as they overcome the sense of failure and anxiety.

In the Japanese context such an intersubjective space to co-create new perspectives is called " $b a$ ", a socio-personal and organic communicative space for co-constructing a new understanding with others (Nonaka \& Toyama, 2003, 2005). In $b a$ individuals engage in organic exchanges of perspectives on a complex situation and co-function to overcome contradictions and dilemmas that emerge in the context. In essence, $b a$ is a shared social space to create emerging relationships and use these relationships to

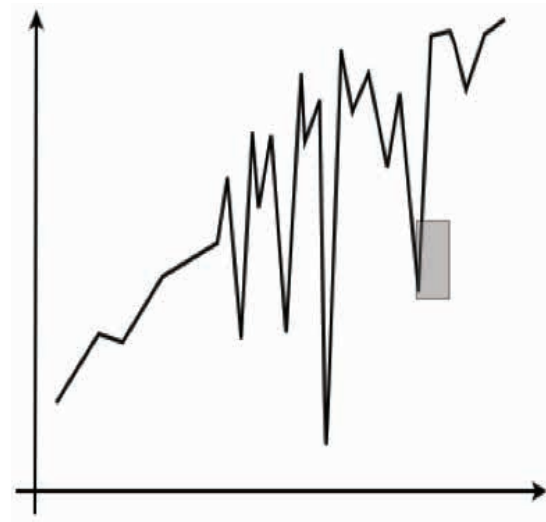

Figure 2: Hypothetical Developmental History of A Teacher 
organically co-construct new meanings in a social context (Inoue, 2015). It has been argued that creating such an inter-subjective space serves as an essential condition for knowledge creation in the Japanese organizations (Nonaka \& Konno, 1998; Nonaka \& Takeuchi, 1995)

Thus, one of the important goals of action research advising can be seen to generate such $b a$ in the way that allows teachers to open up the subjective dimension of their meaning-making in their practice while creating emerging relationships with their advisors so that they can co-reflect and mindfully dance between subjectivity and objectivity. If it is done successfully it can help teachers maintain a healthy and dynamic balance that leads to personal, social and professional development as educators. However, saying it is easy while doing it may not be easy. This would require action research advisors to hold a lot of patience, practical ideas and the sense of humor. Most importantly, it requires a meta-cognitive awareness that any failures in the research process can be tentative no matter how discouraging it may seem from one perspective. For this process to move forward, what holds the key could be to give away the control to the teachers so that they can move forward in their research process with a sense of autonomy, through which they could continue their practice improvement efforts beyond the initial scopes with deep reflections and inner-workings. In this sense, action research advising can be seen to have a highly clinical nature. This issue needs to be further explored and pursued in the field, especially in Western cultures, where such a perspective is rarely heard in teacher education communities.

To conclude what this study suggests is that in mentoring teachers' practice improvement research, we need to always be mindful of the subjective and inter-subjective dimensions of the research process in the way that personal trajectory of teachers could be meaningfully nurtured and supported through multiple phases of the research process. It could be such mindfulness that plays a key role in nurturing healthy professional development of teachers. I envision that this could open up a whole new dimension of teacher education in Western cultures.

\section{References}

[1] David, D. S. (2009). Mindful teaching and teaching mindfulness: A guide for anyone who teaches anything. Summerville, MA: Wisdom Publications

[2] Drapeau. M. (2002). Subjectivity in research: Why not? But... The Qualitative Report, 7, September
[3] Farren, M., \& Crotty, Y. (2014). Researching our own practice: An individual creative process and a dialogic-collaborative process: Self knowledge is the beginning of wisdom. Krishnamurti (1991, p. 196). International Journal of Transformative Research, 1(1), 63-74

[4] Gergen, K. (2001). Psychological science in a postmodern context. American Psychologist, 56, 803-813

[5] Jennings, P. A. (2015). Mindfulness for teachers: Simple skills for peace and productivity in the classroom. New York: W.W. Norton \& Company

[6] Inoue, N. (2015). Beyond actions: Psychology of action research for mindful educational improvement. New York: Peter Lang Publishing

[7] Inoue, N. (2012). Mirrors of the mind: An introduction of mindful ways of thinking. New York: Peter Lang Publishing.

[8] Inoue, N. (2011). Zen and the art of neriage: Facilitating consensus building in mathematics inquiry lessons through lesson study. Journal of Mathematics Teacher Education, 14(1), 5-23

[9] Lewis, C. (2002). Does Lesson Study Have a Future in the United States? Nagoya Journal of Education and Human Development, 1

[10] Lewis, C. (1995). Educating Hearts and Minds: Reflections on Japanese Preschool and Elementary Education. New York: Cambridge University Press

[11] Miles, M. B. \& Huberman, A. M. (1994). Qualitative data analysis. Thousand Oaks, CA: Sage Publications

[12] Nonaka, I. \& Konno, N. (1998) The Concept of "Ba": Building a Foundation for Knowledge Creation. California Management Review, 40(3), 40-54

[13] Nonaka, I., \& Takeuchi, H, (1995). The Knowledge-Creating Company: How Japanese Companies Create the Dynamics of Innovation. New York: Oxford University Press

[14] Nonaka, I. \& Toyama, R. (2003) The knowledge-creation theory revisited: knowledge creation as a synthesizing process. Knowledge Management Research \& Practice, 1(1), 2-10

[15] Nonaka, I. \& Toyama, R. (2005) The theory of the knowledgecreating firm: subjectivity, objectivity and synthesis. Industrial and Corporate Change, 14(3), 419-436

[16] Noffke, S. E. (2009). Revisiting the professional, personal, and political dimensions of action research. In S. E. Noffke \& B. Somekh (Eds.). The SAGE handbook of educational action research. (pp. 6-25). Los Angeles: Sage

[17] Ratner, C. (2002). Subjectivity and objectivity in qualitative methodology. Forum: Qualitative Social Research, 3(3), September

[18] Reagan, T. (2004). Non-Western Educational Traditions: Indigenous Approaches to Educational Throught and Practice (Sociocultural, Political, and Historical Studies in Education) (3rd edition). New York: Routledge

[19] Rechtschaffen, D. (2002). The way of mindful education: Cultivating well-being in teachers and students. New York: W. W. Norton \& Company

[20] Torbert, W. R. (2004). Action Inquiry: The Secret of Timely and Transforming Leadership. San Francisco, CA: Berrett-Koehler Publishers

[21] Whitehead, J. and McNiff, J. (2006). Action research: Living theory: Thousand Oaks, CA: Sage Publications

[22] Yin, R. K. (1989). Case study research: Design and methods. Thousand Oaks, CA Thousand Oaks: Sage Publications 